\title{
Metarhizium anisopliae blastospores are highly virulent to adult Aedes aegypti, an important arbovirus vector
}

\author{
Adriano Rodrigues de Paula', Leila Eid Imad Silva', Anderson Ribeiro', Gerson Adriano da Silva', \\ Carlos Peres Silva ${ }^{2}$, Tariq M. Butt ${ }^{3}$ and Richard lan Samuels ${ }^{1 *}$ (I)
}

\begin{abstract}
Background: The use of entomopathogenic fungi (EPF) for the control of adult mosquitoes is a promising alternative to synthetic insecticides. Previous studies have only evaluated conidiospores against adult mosquitoes. However, blastospores, which are highly virulent against mosquito larvae and pupae, could also be effective against adults.

Methods: Metarhizium anisopliae (ESALQ 818 and LEF 2000) blastospores and conidia were first tested against adult Aedes aegypti by spraying insects with spore suspensions. Blastospores were then tested using an indirect contact bioassay, exposing mosquitoes to fungus-impregnated cloths. Virulence when using blastospores suspended in 20\% sunflower oil was also investigated.

Results: Female mosquitoes sprayed with blastospores or conidia at a concentration of $10^{8}$ propagules $\mathrm{ml}^{-1}$ were highly susceptible to both types of spores, resulting in 100\% mortality within 7 days. However, significant differences in virulence of the isolates and propagules became apparent at $10^{7}$ spores $\mathrm{ml}^{-1}$, with ESALQ 818 blastospores being more virulent than LEF 2000 blastospores. ESALQ 818 blastospores were highly virulent when mosquitoes were exposed to black cotton cloths impregnated with blastospores shortly after preparing the suspensions, but virulence declined rapidly $12 \mathrm{~h}$ post-application. The addition of vegetable oil to blastospores helped maintain virulence for up to $48 \mathrm{~h}$.
\end{abstract}

Conclusion: The results showed that blastospores were more virulent to adult female Ae. aegypti than conidia when sprayed onto the insects or applied to black cloths. Vegetable oil helped maintain blastospore virulence. The results show that blastospores have potential for use in integrated vector management, although new formulations and drying techniques need to be investigated.

Keywords: Arbovirus, Dengue, Biological control, Fungus, Pathogen, Blastospores, Conidia

\section{Background}

Aedes aegypti (Diptera: Culicidae) is a vector of dengue, chikungunya, Zika, and urban yellow fever [1]. In the case of dengue, it has been estimated that 3.9 billion people

\footnotetext{
*Correspondence: richardiansamuels@gmail.com

${ }^{1}$ Laboratório de Entomologia e Fitopatologia, Universidade Estadual do Norte Fluminense Darcy Ribeiro, Campos dos Goytacazes, Rio de Janeiro 28013-602, Brazil

Full list of author information is available at the end of the article
}

are at risk of infection in 129 countries [2,3]. Modeling of dengue virus infections in 2013 gave a figure of 390 million infections per year worldwide (95\% credible interval 284-528 million), of which 96 million (67-136 million) cases were manifested clinically [4].

Application of synthetic insecticides is currently the principal method used to control these insects and thus reduce the incidence of diseases [5]. However, the negative effects of using chemical insecticides, such as the original author(s) and the source, provide a link to the Creative Commons licence, and indicate if changes were made. The images or other third party material in this article are included in the article's Creative Commons licence, unless indicated otherwise in a credit line to the material. If material is not included in the article's Creative Commons licence and your intended use is not permitted by statutory regulation or exceeds the permitted use, you will need to obtain permission directly from the copyright holder. To view a copy of this licence, visit http://creativecommons.org/licenses/by/4.0/. The Creative Commons Public Domain Dedication waiver (http://creativeco mmons.org/publicdomain/zero/1.0/) applies to the data made available in this article, unless otherwise stated in a credit line to the data. 
selection for resistant genotypes, environmental pollution, and human health concerns, have encouraged the search for alternative methods of mosquito control [6]. One alternative is the use of biological control agents, for example, entomopathogens. Products based on the bacteria Bacillus thuringiensis israelensis (Bti) are currently commercialized for the control of larval stages of the mosquito life cycle [7]; however, there are no purely biological control agents available for use against adults. Studies indicate that entomopathogenic fungi (EPF) are promising candidates for the control of adult Aedes, Culex, and Anopheles [8]. However, many studies which propose the use of EPF as a part of integrated vector management (IVM) still need to be evaluated in the field, which includes operational feasibility and economic assessments, to provide evidence to support implementation [9].

The vast majority of EPF sold commercially (targeting agricultural pests) belong to the genera Metarhizium and Beauveria [10]. The infective propagules consist of either conidia or blastospores, which are produced on solid or liquid substrates, respectively [11]. Blastospores have several advantages over conidia. Firstly, they can be produced quickly, taking 2-3 days, whereas conidial production can take 14-21 days. Some studies have shown conidia to be more virulent than blastospores, whilst others have shown the converse or that they are equally virulent [12-15]. Blastospores have been shown to be more virulent to adult stages than to juveniles, the opposite being true for conidia [16]. When comparing mosquito larvae and pupae, blastospores were more virulent that conidia, independent of mosquito species tested $[15,17$, 18].

However, one of the drawbacks with using blastospores for biological control is that they are more susceptible to environmental stress, possibly due to the thinner cell walls, and consequently they are less stable than aerial conidia [11]. All previous studies of EPF targeting adult mosquitoes have focused on evaluating aqueous or oilformulated conidia, revealing differences in the efficacy of the formulations and virulence of different isolates of Beauveria or Metarhizium against, for example, Ae. aegypti [19], Aedes albopictus, Culex pipiens [20], Anopheles gambiae sensu stricto, Anopheles arabiensis, and Culex quinquefasciatus [21].

The potential for using black cloths impregnated with Metarhizium anisopliae conidia for the control of adult $A e$. aegypti has been evaluated under laboratory and simulated field conditions by our group [22-24]. Mosquitoes are attracted to land on the fungus-impregnated black cloths, thus becoming infected, and their survival rates are rapidly reduced [25]. Formulating conidia in vegetable oil + isoparaffin significantly increased persistence in the field [24].

Due to the lack of any information on the pathogenicity and virulence of $M$. anisopliae blastospores against adult mosquitoes, the present study was carried out to firstly ascertain whether blastospores were pathogenic to Ae. aegypti adults, and then to compare the virulence of the blastospores and conidia of two different $M$. anisopliae isolates. New biological control agents and novel innovative strategies are urgently needed to reduce populations of disease-transmitting mosquitoes.

\section{Methods}

\section{Mosquito collection and rearing}

Adult Ae. aegypti used in this study were reared from eggs collected in the field (university campus), as these were considered fitter and more representative of natural populations than the more homogeneous, laboratory-reared mosquitoes. The eggs were collected using ovitraps, which consist of black plastic plant pots $(12 \mathrm{~cm}$ in diameter $\times 15 \mathrm{~cm}$ in height) with four wooden strips or paddles $(3 \times 12 \mathrm{~cm})$ placed vertically within the pots, providing highly conducive landing platforms for gravid, ovipositing females (see Additional file 1). Approximately $300 \mathrm{ml}$ of tap water was added to each ovitrap before placing it outdoors at sites protected from rain and direct sunlight close to the university insectary (latitude: $-21^{\circ} 45^{\prime} 8.17^{\prime \prime} \mathrm{S}$; longitude: $\left.-41^{\circ} 19^{\prime} 49.58^{\prime \prime} \mathrm{W}\right)$.

After 5 days, the paddles with eggs were collected and dried at room temperature for $24 \mathrm{~h}$. To initiate egg hatching, the paddles were submerged in water, and the emergent larvae were maintained in plastic trays (approximately 100 larvae per $100 \mathrm{ml}$ ) and fed on freshly ground, autoclaved commercial fish food (Nuvilab, São Paulo, Brazil; $0.05 \mathrm{~g} / \mathrm{l}$ ). Pupae were separated into water-filled beakers and transferred to cages prior to adult emergence. Adults were maintained in cages with $10 \%$ sucrose wick feeders. Recently emerged (2-3 days old) females that had been maintained in cages with males were initially anesthetized using a stream of $\mathrm{CO}_{2}$ and then placed on top of a glass plate at a temperature of approximately $6{ }^{\circ} \mathrm{C}$ with ice packs underneath the plate to maintain the mosquitoes in a dormant state for a maximum of $5 \mathrm{~min}$. The females were then separated from males with the aid of an LED illuminated magnifying glass.

\section{Fungal isolates}

Metarhizium anisopliae (isolate ESALQ 818) was obtained from the Universidade de São Paulo-Escola Superior de Agricultura "Luiz de Queiroz" (ESALQ) in Piracicaba, São Paulo, Brazil. Conidia of this isolate have been previously shown to be highly virulent to adult Ae. aegypti [19]. Metarhizium anisopliae isolate LEF 
2000 was obtained from a soil sample in Campos dos Goytacazes, Brazil (latitude: $-21^{\circ} 45^{\prime} 8.17^{\prime \prime} \mathrm{S}$; longitude: $\left.-41^{\circ} 19^{\prime} 49.58^{\prime \prime} \mathrm{W}\right)$.

\section{Preparation of conidia}

All of the following methods were carried out using a sterile flow hood with materials that had been previously autoclaved $\left(20 \mathrm{~min}\right.$ at $\left.121{ }^{\circ} \mathrm{C}\right)$ where appropriate. Both isolates of $M$. anisopliae were initially cultured on Sabouraud dextrose agar (SDA: dextrose $10 \mathrm{~g}$, peptone $2.5 \mathrm{~g}$, yeast extract $2.5 \mathrm{~g}$, agar $20 \mathrm{~g}$ in $1 \mathrm{l} \mathrm{H}_{2} \mathrm{O}$ ) for 15 days at $27{ }^{\circ} \mathrm{C}$. SDA was autoclaved for $20 \mathrm{~min}$ at $121^{\circ} \mathrm{C}$ before use. Conidia were then harvested from the solid media using a spatula and suspended in $5 \mathrm{ml}$ of $0.01 \%$ aqueous Tween 20. This suspension was used to inoculate $25 \mathrm{~g}$ of sterile parboiled rice (autoclaved as above) $+10 \mathrm{ml}$ distilled water in a $250 \mathrm{ml}$ conical flask. The flasks were incubated at $27{ }^{\circ} \mathrm{C}$ for 15 days before transferring the inoculated rice to brown paper bags $(18 \times 9 \mathrm{~cm}$; Fasapel Ltd., São Paulo, Brazil), and humidity was reduced using a forced-air incubator at $34{ }^{\circ} \mathrm{C}$ for 24 h before harvesting the conidia using an MR-5 Mycoharvester ${ }^{\circledR}$ (Mycoharvester, UK). Dry conidia were suspended in $0.01 \%$ aqueous Tween 20, and the concentration was determined using a Neubauer hemocytometer. On average, $0.1 \mathrm{~g}$ of dry conidia was equivalent to approximately $5 \times 10^{8}$ conidia $\mathrm{ml}^{-1}$. The fungal concentrations used in assays were $1 \times 10^{7}$ conidia $\mathrm{ml}^{-1}$ or $1 \times 10^{8}$ conidia $\mathrm{ml}^{-1}$. Viability tests were carried out by plate counting, and only batches with $>90 \%$ germination were used in experiments.

\section{Production of blastospores}

Conidia harvested from 15-day cultures were used to initiate the production of blastospores. Blastospores were produced in corn steep liquid medium consisting of 3\% $(\mathrm{v} / \mathrm{v})$ corn steep liquor (Sigma-Aldrich, Brazil), $4 \%$ yeast extract (w/v), and $4 \%$ glucose $(\mathrm{w} / \mathrm{v})$. Briefly, $500 \mu \mathrm{l}$ of a conidial suspension $\left(1 \times 10^{7} \mathrm{ml}^{-1}\right)$ was added to a $250 \mathrm{ml}$ Erlenmeyer flask containing $50 \mathrm{ml}$ of culture medium. The flask was incubated at $27{ }^{\circ} \mathrm{C}$ in an orbital shaker at $152 \mathrm{rpm}$, and blastospores were harvested after 3 days. The blastospores were separated from the hyphal fragments using a Miracloth filter (Sigma-Aldrich, Brazil), and yield was estimated using a Neubauer hemocytometer. A final concentration of $1 \times 10^{7}$ or $1 \times 10^{8}$ blastospores $\mathrm{ml}^{-1}$ was used in the assays for both isolates. For the experiments to test the effects of vegetable oil, blastospores were suspended in $0.01 \%$ Tween 20 with or without $20 \%$ sunflower oil (Sadia ${ }^{\circledR}$, Brazil). Before use, blastospores suspended in oil + Tween 20 were vigorously agitated using a vortex mixer to form an emulsion, which was immediately applied to the cloths.

\section{Spraying mosquitoes with blastospore and conidial suspensions}

Female Ae. aegypti were exposed to $M$. anisopliae (ESALQ 818 or LEF 2000) by spraying with either conidial or blastospore suspensions. Cohorts consisting of 10 mosquitoes were first anesthetized using a stream of $\mathrm{CO}_{2}$ for $30 \mathrm{~s}$ according to Paula et al. [19]. The anesthetized mosquitoes were then placed on a chilled platform as stated above. Females were then quickly transferred to a Petri dish lined with a sterile filter paper before being sprayed using a Potter tower (Burkart Ltd., UK) with $1 \mathrm{ml}$ of either $M$. anisopliae conidia or blastospores at two different concentrations $\left(1 \times 10^{7}\right.$ or $1 \times 10^{8}$ propagules $\left.\mathrm{ml}^{-1}\right)$ in $0.01 \%(\mathrm{v} / \mathrm{v})$ aqueous Tween 20 . Control insects were sprayed with $1 \mathrm{ml}$ of $0.01 \%$ Tween 20 only. The number of fungal propagules per $\mathrm{cm}^{2}$ targeting the mosquitoes on the filter paper was estimated by randomly sampling five $1 \mathrm{~cm}^{2}$ pieces of filter paper after each experiment. Each piece of filter paper was placed in an Eppendorf tube with $1 \mathrm{ml}$ of $0.01 \%$ Tween 20, which was then agitated vigorously using a vortex mixer for $1 \mathrm{~min}$. The average number of conidia or blastospores per $\mathrm{cm}^{2}$ were estimated using a hemocytometer.

Mosquitoes were then carefully transferred to plastic pots $(12 \times 7 \mathrm{~cm})$ with mesh netting screen lids (see Graphical abstract). The pots were kept in an incubator $\left(25^{\circ} \mathrm{C} ; 70 \pm 10 \%\right.$ relative humidity $[\mathrm{RH}] ; 12 \mathrm{~h} / 12 \mathrm{~h}$ light/ dark). The mosquitoes were fed daily with $10 \%$ sucrose offered on filter paper discs placed on the surface of the netting. Mosquito survival was assessed daily for 7 days. These experiments were performed three times for each isolate, with 30 insects used per treatment/isolate $(n=90$ insects per treatment/isolate; treatment $N=180$; control $N=180$ ).

\section{Exposing mosquitoes to blastospore-impregnated black cloths at different times after application to the cloths} In this test, ESALQ 818 blastospores were used to impregnate black cloths, to which adult female $A e$. aegypti were subsequently exposed. Only ESALQ 818 blastospores were used in these experiments, as these propagules were significantly more virulent than LEF 2000 blastospores. The survival of mosquitoes exposed to the cloths at different times after application of blastospores to the cloths was evaluated to monitor the virulence of the inoculum over time.

Black cotton cloths $(8 \times 6 \mathrm{~cm})$ were autoclaved at $121{ }^{\circ} \mathrm{C}$ for $15 \mathrm{~min}$ and then impregnated with blastospores by brushing each side of the cloth with 
suspensions of $5 \mathrm{ml}$ of $1 \times 10^{7}$ blastospores $\mathrm{ml}^{-1}$ in $0.01 \%$ aqueous Tween 20. One set of cloths was immediately used for bioassays, whilst two other sets of cloths were left to dry at room temperature (maximum: $26.9^{\circ} \mathrm{C}$ minimum: $23.8{ }^{\circ} \mathrm{C}$; maximum: $85 \% \mathrm{RH}$ and minimum: $71.6 \%$ $\mathrm{RH})$ for either $12 \mathrm{~h}$ or $24 \mathrm{~h}$. Three sets of control cloths were treated with $5 \mathrm{ml}$ of $0.01 \%$ aqueous Tween 20 . One set was used immediately and the other two sets were left to dry for either $12 \mathrm{~h}$ or $24 \mathrm{~h}$.

The bioassay was carried out by suspending a single black cloth vertically inside each plastic pot $(12 \times 7 \mathrm{~cm})$ before releasing 10 female mosquitoes into the pot. This methodology was the same as that developed by Paula et al. [25]. Female mosquitoes were previously anesthetized as described above before placing in the pots. The mosquitoes were able to move freely around the pot, which was kept in an incubator $\left(25^{\circ} \mathrm{C} ; 70 \pm 10 \% \mathrm{RH}\right.$; $12 \mathrm{~h} / 12 \mathrm{~h}$ light/dark). The insects were fed daily with $10 \%$ sucrose offered on filter paper discs placed on the surface of the white mesh netting of the lids. After a period of $48 \mathrm{~h}$, the black cloths were carefully removed from the plastic pots. Mosquito survival was assessed daily for 7 days.

For each time point $(0 \mathrm{~h}, 12 \mathrm{~h}$, and $24 \mathrm{~h}$ after impregnating the cloths with fungus), 30 mosquitoes were used (10 per pot). Mosquitoes were also exposed to control cloths at the three different time points. Therefore, a total of 90 mosquitoes were used per experimental treatment (three time periods) and 90 controls (three time periods). The experiments were carried out three times $(N=270$ blastospore-treated mosquitoes; $N=270$ controls).

\section{Application of blastospore suspensions in oil to black cloths}

This bioassay was carried out as stated above, except that the blastospores were suspended in $20 \%$ sunflower oil + aqueous Tween 20 (0.01\%) and then applied to black cloths as an emulsion. The survival rates of mosquitoes exposed to these cloths were then compared to mosquitoes exposed to blastospores suspended in Tween 20 only. This experiment evaluated the virulence of the blastospores applied to the cloths at different times following application to the cloths. Mosquitoes were placed in pots with blastospore-impregnated cloths at $0 \mathrm{~h}$ (immediately after preparing the cloths), $12 \mathrm{~h}, 24 \mathrm{~h}$, and $48 \mathrm{~h}$ after applying blastospores to the cloths. Control applications of $20 \%$ sunflower oil + Tween 20 without blastospores or Tween 20 without blastospores were also used at each time point. Three cohorts (pots with 10 mosquitoes each) were used for each time point. Therefore, a total of 120 mosquitoes were used per experimental treatment (four time periods) and 120 controls (four time periods). The experiments were carried out three times $(N=360$ blastospore-treated mosquitoes; $N=360$ controls).

\section{Blastospore germination and colony growth}

Freshly harvested ESALQ 818 and LEF 2000 blastospores were suspended in $0.01 \%$ aqueous Tween 20 with and without $20 \%$ sunflower oil, vortex mixed vigorously for $1 \mathrm{~min}$, and then $100 \mu \mathrm{l}$ aliquots of the suspensions were inoculated onto SDA plates. The plates were then incubated for $6 \mathrm{~h}$ at $27^{\circ} \mathrm{C}$. The germination rates after this time period were evaluated using an inverted microscope (Biovera, São Paulo, Brazil). Three fields of view were selected randomly for each plate counted and evaluations were carried out three times to calculate the mean germination rates. A 6-h incubation time was chosen for counting as germination rates were normally higher than $50 \%$ but less than $100 \%$ in preliminary experiments. This time period allowed comparisons to be made between the different treatments and isolates.

Fungal radial growth experiments were performed using both ESALQ 818 and LEF 2000 blastospores at a concentration of $1 \times 10^{6}$ blastospores $\mathrm{ml}^{-1}$ with and without $20 \%$ sunflower oil in $0.01 \%$ aqueous Tween 20 , prepared as stated above. For this experiment, a $15 \mu \mathrm{l}$ aliquot of each suspension was inoculated in the center of each Petri dish ( $9 \mathrm{~cm}$ diameter) containing SDA. The plates were incubated at $27{ }^{\circ} \mathrm{C}$ and $70 \pm 10 \% \mathrm{RH}$ for a total of 10 days. Three plates were used for each treatment and all experiments were performed three times. Radial growth $(\mathrm{mm})$ was estimated daily using Vernier calipers, measuring growth rates from the center of the colony to the external border.

\section{Statistical analysis}

All data analyses were performed with GraphPad Prism 6.0 software package (GraphPad Software, San Diego, CA, USA). For survival data, the homogeneity of the repetitions was analyzed using the log-rank test at a 95\% significance level. Homogenous results were then pooled for survival curve analysis. The average survival time $\left(S_{50}\right)$ was calculated using the Kaplan-Meier method [33]. Statistical differences between the survival curves of different treatments were compared using the log-rank test. The results for all the control groups were pooled and only one survival curve was shown for each figure.

Comparison of Ae. aegypti end-point survival percentages for the different treatments was assessed using one-way analysis of variance (ANOVA). Mean germination rates and mean radial growth were compared 
using unidirectional analysis of variance. Differences between groups were considered significant if the $P$ value was $\leq 0.05$ (Duncan's post hoc test).

\section{Results}

The first bioassay employed a spray application technique to evaluate the virulence of blastospores and conidia of both isolates. The results demonstrated that both isolates and both types of propagules were highly virulent when mosquitoes were sprayed with

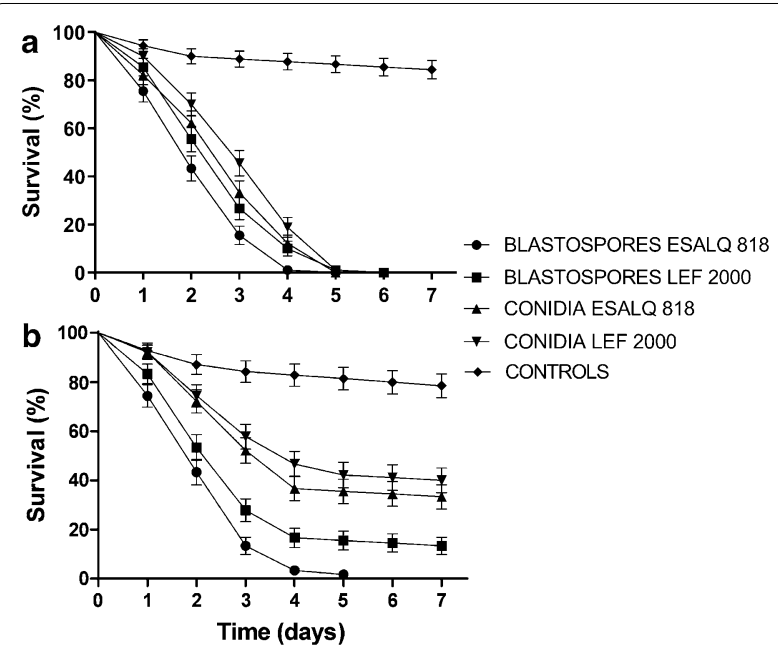

Fig. 1 a Survival curves of Aedes aegypti females sprayed with conidia or blastospore suspensions of two Metarhizium anisopliae isolates (ESALQ 818 and LEF 2000) at a concentration of $1 \times 10^{8}$ propagules $\mathrm{ml}^{-1}$. b Survival curves of Ae. aegypti females sprayed with conidia or blastospore suspensions of two Metarhizium anisopliae isolates (ESALQ 818 and LEF 2000) at a concentration of $1 \times 10$ propagules $\mathrm{ml}^{-1}$. Control data for all treatment groups were combined and are represented as a single survival curve. Error bars are \pm SD (standard deviation of the mean)
$1 \times 10^{8}$ propagules $\mathrm{ml}^{-1}$ (Fig. 1a). This concentration of propagules was estimated to give a coverage of $1.7 \times 10^{6} \pm 1.4 \times 10^{5}$ conidia/blastospores $\mathrm{cm}^{2}$ when counting propagules from the filter paper onto which the mosquitos were placed on the platform of the Potter tower.

The lowest median survival time $\left(S_{50}\right)$ was seen when mosquitos were sprayed with ESALQ 818 blastospores ( 2 days), whilst a value $S_{50}$ of 3 days was seen for the three other treatments: ESALQ 818 conidia, LEF 2000 blastospores and LEF 2000 conidia (Table 1). Evaluations of survival rates when using this concentration of propagules was performed on day 3 , as all fungus-treated mosquitoes had died by day 7 . When comparing survival rates for all treatments and controls on day 3 of the experiment, ESALQ 818 blastospores were seen to be significantly more virulent $\left(F_{(4,14)}=75.15, P<0.0001\right)$ with only $15 \%$ of the insects surviving at this time (Table 1 ). The survival rates of mosquitoes sprayed with LEF 2000 blastospores or ESALQ 818 conidia was $26.6 \%$ and $33.3 \%$, respectively, with no significant difference between these two treatments. LEF 2000 conidia were the least virulent, with $45 \%$ survival recorded on day 3 .

In order to more clearly differentiate the virulence of the isolates and propagules, spray applications were carried out at a lower concentration $\left(1 \times 10^{7}\right.$ propagules $\mathrm{ml}^{-1}$ ). This concentration of propagules was estimated to give a coverage of $8 \times 10^{5} \pm 1.3 \times 10^{5}$ conidia/ blastospores $\mathrm{cm}^{2}$ when counting propagules from the filter paper onto which the mosquitos were placed on the platform of the Potter tower.

Bioassays at this concentration of propagules demonstrated that ESALQ 818 blastospores were significantly more virulent than ESALQ 818 conidia, LEF 2000 blastospores, or LEF 2000 conidia $\left(X^{2}=138.7, P<0.0001\right)$. ESALQ 818 blastospore applications resulted in 100\%

Table 1 Aedes aegypti survival rates on day 3 and day 7 following different treatments

\begin{tabular}{|c|c|c|c|c|}
\hline \multirow[t]{2}{*}{ Treatments/isolate } & \multicolumn{2}{|l|}{ Day 3} & \multicolumn{2}{|l|}{ Day 7} \\
\hline & $\begin{array}{l}\text { Survival }(\%) \pm S D \\
1 \times 10^{8} \text { conidia }^{-1}\end{array}$ & $S_{50}$ (days) & $\begin{array}{l}\text { Survival }(\%) \pm S D \\
1 \times 10^{7} \text { conidia }^{-1}\end{array}$ & $S_{50}$ (days) \\
\hline Blastospores ESALQ 818 & $15.5 \pm 3.51 \mathrm{a}$ & 2 & 0 & 2 \\
\hline Conidia ESALQ 818 & $33.3 \pm 5.29 b$ & 3 & $36.6 \pm 8.45 b$ & 4 \\
\hline Blastospores LEF 2000 & $26.6 \pm 7.81 b$ & 3 & $16.6 \pm 9.39 a$ & 3 \\
\hline Conidia LEF 2000 & $45.5 \pm 6.65 c$ & 3 & $42.2 \pm 6.54 c$ & 4 \\
\hline Controls & $88 \pm 1.52 d$ & nd & $87.7 \pm 2.14 \mathrm{~d}$ & ND \\
\hline
\end{tabular}

Results are shown as the mean survival rates (\% \pm SD) after spraying mosquitoes with $1 \times 10^{8} \mathrm{ml}^{-1}$ (conidia or blastospores) of two isolates (ESALQ 818 and LEF 2000 ) on day 3 or day 7 following spraying of mosquitoes with $1 \times 10^{7} \mathrm{ml}^{-1}$ (conidia or blastospores)

The mean survival percentages followed by different letters indicate statistical differences when comparing values (columns) using ANOVA followed by Duncan's post hoc ( $5 \%$ level). Control data for each treatment group were combined, and a single mean survival rate was calculated

nd not determined 
mortality on day 5 of the bioassay (Fig. 1b). In these experiments, the survival rates for the controls were on average $87 \%$. The mean end-point survival rates (on day 7) were significantly different when comparing all treatments, including the controls (Table 1). The ANOVA also showed that mean survival rates for all fungal treatments and their respective controls were significantly different $\left(F_{(4,14)}=465.3, P<0.0001\right)$. The lowest $S_{50}$ value was seen for ESALQ 818 blastospores ( 2 days). The $S_{50}$ for LEF 2000 blastospores was 3 days, whilst the other two fungal treatments, LEF 2000 conidia and ESALQ 818 conidia, both had an $S_{50}$ value of 4 days (Table 1). This information was important for the development of the next bioassay testing the virulence of blastospores applied to black cloths to which the mosquitoes were subsequently exposed. As the aim of the investigation was to evaluate blastospores as putative biological control agents for use against adult mosquitoes, only ESALQ 818 blastospores (most virulent propagules) were used in the following bioassays.

Black cotton cloths were impregnated with $1 \times 10$ blastospores $\mathrm{ml}^{-1}$ in Tween $20(0.01 \% \mathrm{v} / \mathrm{v})$. This concentration of propagules was estimated to give a coverage of $9 \times 10^{6} \pm 8 \times 10^{5}$ blastospores $\mathrm{cm}^{2}$ when

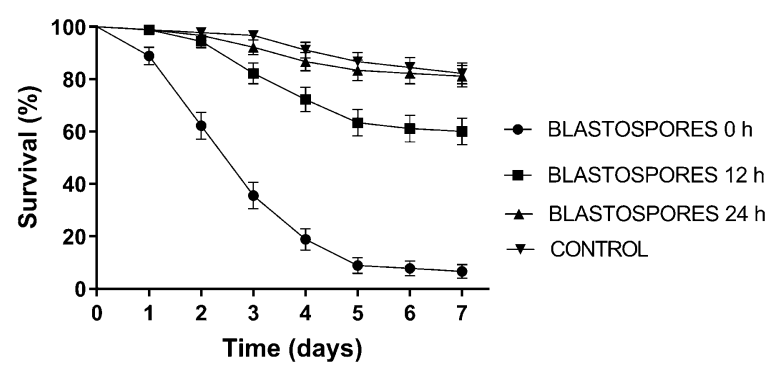

Fig. 2 Survival curves of Aedes aegypti females following exposure to ESALQ 818 blastospore $\left(1 \times 10^{7} \mathrm{ml}^{-1}\right)$-impregnated black cotton cloths immediately after applying the blastospore suspensions to the cloths $(0 \mathrm{~h}), 12 \mathrm{~h}$ after preparing the cloths, and $24 \mathrm{~h}$ after preparing the cloths. Control data for all treatment groups were combined and represented as a single survival curve. Error bars are \pm SD (standard deviation of the mean) applying $5 \mathrm{ml}$ of the fungal suspension using a paintbrush to the cloths. When exposing mosquitoes to blastosporeimpregnated black cloths, a significant reduction in survival rates $\left(X^{2}=207.5, P<0.0001\right)$ was observed only when mosquitoes were placed in pots with cloths that had been recently treated with blastospores $(0 \mathrm{~h})$. The survival rate for this treatment was $8.8 \%$, whereas mosquito survival following exposure to cloths 12 and $24 \mathrm{~h}$ after application of blastospores resulted in $61 \%$ and $81 \%$ survival, respectively (Fig. 2). Only the 0 -h treatment generated a $S_{50}$ value, which was 3 days (Table 2). The endpoint survival rates for all treatments were significantly different $\left(F_{(3,11)}=956.3, P<0.0001\right)$; however, the survival rates of mosquitoes exposed to cloths $24 \mathrm{~h}$ after application of the fungus were not significantly different from the control survival rates.

In an attempt to improve blastospore efficiency, these propagules were then tested following the addition of $20 \%$ vegetable oil to the suspensions. This oil + Tween 20 formulation was tested at four time periods postapplication to the cloths: $0,12,24$, and $48 \mathrm{~h}$. Mosquito survival curves are shown in Fig. 3. The sharpest decline in survival rates was seen when exposing mosquitoes to

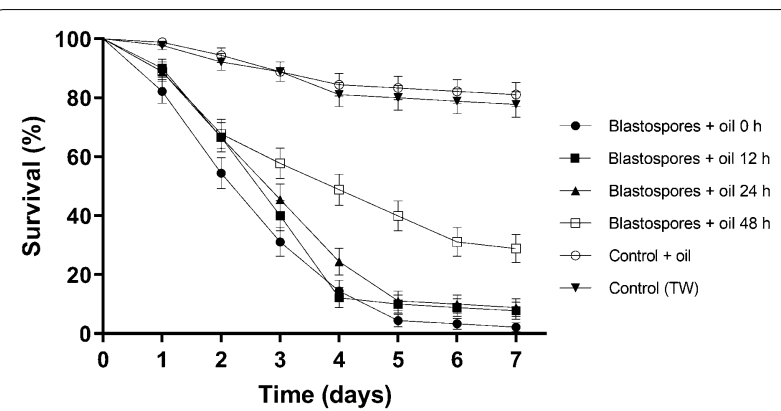

Fig. 3 Survival curves of Aedes aegypti females following exposure to ESALQ 818 blastospore $\left(1 \times 10^{7} \mathrm{ml}^{-1}\right)$-impregnated black cotton cloths with and without the addition of $20 \%$ sunflower oil to the suspensions. Mosquitoes were exposed to the cloths immediately after application of fungi to the cloths ( $0 \mathrm{~h}$ ), or $12 \mathrm{~h}$ later, $24 \mathrm{~h}$ later, or $48 \mathrm{~h}$ later. Control data for all treatment groups were combined and represented as a single survival curve. Error bars are \pm SD (standard deviation of the mean)

Table 2 Aedes aegypti survival rates following exposure to blastospores at different times after applying the suspensions to the cloths

\begin{tabular}{lllll}
\hline Drying time & Blastospores $0 \mathrm{~h}$ & Blastospores 12 $\mathrm{h}$ & Blastospores 24h & Control \\
\hline Survival (\%) $\pm \mathrm{SD}$ & $8.8 \pm 9.97 \mathrm{a}$ & $61.1 \pm 4.32 \mathrm{~b}$ & $81.1 \pm 1.61 \mathrm{C}$ & $82.2 \pm 2.36 \mathrm{C}$ \\
$\mathrm{S}_{50}$ & 3 & nd & nd & nd
\end{tabular}

End-point survival rates $(\% \pm S D)$ and median survival times $\left(S_{50}\right)$ of female Ae. aegypti 7 days after exposure to cloths impregnated with ESALQ 818 blastospores at a concentration of $1 \times 10^{7}$ propagules $\mathrm{ml}^{-1}$. The cloths were placed in the pots immediately $(0 \mathrm{~h}), 12 \mathrm{~h}$, or $24 \mathrm{~h}$ after applying blastospores to the cloths. Mean survival percentages followed by different letters indicate statistical differences when comparing values using ANOVA followed by Duncan's post hoc (5\% level). Control data for all treatment groups were combined, and a single mean survival rate was calculated

nd not determined 
blastospore-impregnated cloths immediately after applying the suspension to the cloths, as had been previously observed for blastospores in Tween 20 only (Fig. 2). For mosquitoes exposed to cloths immediately after the application of blastospores $(0 \mathrm{~h})$, survival declined rapidly, with only $4 \%$ of the mosquitoes remaining alive by day 7 of the experiment (Fig. 3); this value was significantly lower than all other treatments when comparing survival curves using log-rank analysis $\left(X^{2}=316.6\right.$, $P<0.0001)$. Exposing mosquitoes to cloths $12 \mathrm{~h}$ and $24 \mathrm{~h}$ after application of blastospores resulted in similar survival curves, with $8 \%$ and $11 \%$ end-point survival rates, which were not significantly different from each other (Table 3). Mosquitoes exposed to blastospores $48 \mathrm{~h}$ after preparation of the cloths, resulted in a survival rate of $28 \%$ on the seventh day of evaluation (Fig. 3 and Table 3 ). Although this survival rate was significantly higher than that of the other time points, it was still significantly lower than that of the controls (Table 3: $F_{(20,6)}=700.1$, $P<0.0001)$. Although the end-point survival rates were significantly lower for the 0 -h treatment group, $S_{50}$ values for $0 \mathrm{~h}, 12 \mathrm{~h}$, and $24 \mathrm{~h}$ were all 3 days. The $S_{50}$ for blastospores + oil tested $48 \mathrm{~h}$ after applying the formulation to the cloths was 4 days (Table 3 ).

The germination and growth rates of blastospores of both isolates were similar when suspended in Tween 20 only or Tween $20+$ sunflower oil (see Additional file 1: Table S1 and Figure S1).

\section{Discussion}

This study shows for the first time that $M$. anisopliae blastospores are pathogenic to adult Ae. aegypti and that blastospores of both fungal isolates tested here were

Table 3 Aedes aegypti survival rates following exposure to blastospores formulated in oil at different times after preparation

\begin{tabular}{lll}
\hline Treatments & Mean survival (\%) $\pm S D$ & $S_{50}$ (days) \\
\hline Blastospores + oil 0 h & $4 \pm 9.75 \mathrm{a}$ & 3 \\
Blastospores + oil 12 h & $8.8 \pm 10.6 \mathrm{~b}$ & 3 \\
Blastospores + oil 24 h & $11.1 \pm 8.37 \mathrm{~b}$ & 3 \\
Blastospores + oil 48 h & $28.8 \pm 7.9 \mathrm{c}$ & 4 \\
Control + oil & $81.1 \pm 2.76 \mathrm{~d}$ & nd \\
Control (TW) & $82.2 \pm 2.28 \mathrm{~d}$ & nd \\
\hline
\end{tabular}

Survival rates $(\% \pm \mathrm{SD})$ and median survival times $\left(S_{50}\right)$ of female $A$ e. aegypti 7 days after exposure to cloths impregnated with ESALQ 818 blastospores at a concentration of $1 \times 10^{7}$ propagules $\mathrm{ml}^{-1}$, with and without the addition of $20 \%$ sunflower oil to the suspensions. Mosquitoes were exposed to the cloths immediately after application of fungi to the cloths $(0 \mathrm{~h})$ or $12 \mathrm{~h}, 24 \mathrm{~h}$, or $48 \mathrm{~h}$ later. Mean survival percentages followed by different letters indicate statistical differences when comparing values using ANOVA followed by Duncan's post hoc ( $5 \%$ level). Control data for each oil treatment group (four data sets) were combined, and the single mean survival rate was calculated

nd not determined, TW Tween 20 more virulent than conidiospores. The initial tests were carried out by spraying mosquitoes with conidial and blastospore suspensions, in order to confirm and compare the virulence of the fungal propagules. Our research group has used this spray infection technique for certain types of bioassays, but the main aim of our research is to develop traps which reduce adult mosquito survival by attracting the mosquitos to land on fungus-impregnated surfaces [22, 23]. Mosquitoes are attracted to dark surfaces, and studies have shown that Ae. aegypti females land on fungus-impregnated black cloths at the same rate as on untreated cloths [25]. Although we do not discount the option of space spraying of fungi, innovative strategies could prove to be more effective in controlling mosquito adult populations to reduce arbovirus transmission.

In the search for highly virulent isolates or propagule types, it is important to consider that mosquitoes probably land on fungus-impregnated surfaces for short periods, but even short-term contact with the fungus could reduce vectorial capacity. The extrinsic incubation period for dengue transmission by Ae. aegypti is between 8 and 12 days [26]. Even though it is not crucial to rapidly kill virus vectoring mosquitoes that have taken their first blood meal, it is still preferable to kill them quickly. Mosquitoes in a range of nutritional states and levels of virus development in their bodies are also targets for EPF. Entomopathogenic fungal infections can reduce vectorial capacity before killing the host mosquito by reducing propensity to feed and fecundity [27].

Previous studies have shown that blastospores are more virulent than conidia when tested against $A e$. aegypti larvae [15] or pupae [18]. Although it is not clear exactly why blastospores are more virulent than conidia to these aquatic stages of the mosquito life cycle, blastospores are hydrophilic and are thus more easily dispersed in an aquatic environment than hydrophobic conidia, which require the use of surfactants to disperse in water. Another important factor is that blastospores produce large amounts of mucilage, which improves adhesion to the host integument [15]. Blastospores germinate faster than conidia, which can also be an advantage in initiating disease [28]. Rapid germination and penetration of the cuticle enables the fungus to reduce its exposure time to highly damaging UV radiation and low relative humidity $[29,30]$. The results of the current study demonstrated that blastospores in water were highly virulent only when used immediately after application to the cloths. However, the addition of sunflower oil to the suspensions resulted in significant improvements in the maintenance of blastospore virulence.

Oil formulations have been previously shown not only to increase conidial shelf life [31] but also to protect conidia in the field from adverse environmental 
conditions such as low relative humidity [32]. Formulation of conidia in oil was one of the foundations of the success of Metarhizium (Green Muscle ${ }^{\circledR}$ ) for the control of the desert locust (Schistocerca gregaria) in Africa [33]. Here, we decided to test blastospores suspended in $20 \%$ sunflower oil + Tween 20 applied to the black cloths. However, before using oil-formulated blastospores against mosquitoes, we first checked whether the oil had any adverse effects on blastospore germination or fungal growth. Blastospores germinated at similar rates in the presence or absence of oil, whilst the growth rates of the fungus with and without oil were not significantly different (see Additional file 1: Table S1; Figure S1).

The deployment of black cloths impregnated with conidia has been shown to be a promising strategy for reducing mosquito survival. In one of the first studies to investigate the use of fungus-impregnated black cloths in human habitations, Beauveria bassiana was shown to infect and kill significant numbers of Anopheles stephensi adults [34]. More recently, Paula et al. [23] tested black cloths impregnated with $M$. anisopliae conidia in rooms simulating a human habitation. Fungus-impregnated cloths deployed in association with an attractive lure $\left(\right.$ AtrAedes $\left.^{\circledR}\right)$ reduced mosquito survival over a 7 -day period to $32 \%$, whilst black cloths impregnated with $M$. anisopliae conidia without lures resulted in a $48 \%$ survival rate. This approach is highly promising as an alternative to chemical control methods.

Blastospores are highly virulent against adult $A e$. aegypti, and the addition of vegetable oil helped maintain virulence for up to $48 \mathrm{~h}$ after preparation of fungal suspensions. It is possible that the oil helps maintain the integrity of the blastospores, which are sensitive to desiccation [35] following application to the black cloths. Several hypotheses have been proposed to explain how the addition of oil enhances the efficiency of conidia to target pests. A thin oil layer might prevent the desiccation of fungal propagules by slowing evaporation, thus giving conidia more time to germinate and infect the host [36]. Oils are also known to disrupt the protective layer of epicuticular waxes on the insect cuticle or leaching of cuticle compounds, diluting antifungal compounds present in the epicuticle and thus stimulating germination and subsequent infection [37]. It has also been reported that oil formulations improve adhesion of spores to the lipophilic insect cuticle [38]. Spores may also disseminate more easily to infect susceptible parts of the insect body, such as the intersegmental membranes, when formulated in oil [37, 38]. When blastospores were suspended in $20 \%$ vegetable + aqueous surfactant (Tween 20), the emulsion, which was subsequently applied to black cloths, extended the effectiveness of the blastospores over time. It is also interesting to note that fungal virulence can be affected by factors such as culture conditions (nutrients, $\mathrm{pH}$, temperature) $[39,40]$. Conidia produced on rice grains were more virulent to Ae. aegypti larvae than those produced on standard laboratory media such as Sabouraud dextrose agar [41]. We are currently investigating the effects of different media on blastospore virulence. Following production of the blastospores, it will be necessary to study drying techniques, which are known to improve shelf life [42] .

\section{Conclusions}

Blastospores were more virulent than conidia to adult female Ae. aegypti when sprayed onto the insects. Blastospores were also virulent when applied to black cloths onto which mosquitoes landed and became infected. The addition of vegetable oil clearly enhanced the virulence of blastospores, suggesting that it improved adhesion to the insect cuticle and probably created a microclimate conducive for germination. Although these results are preliminary, they show that blastospores have potential for use in integrated vector management. However, new formulations and drying techniques need to be investigated to maintain virulence for longer periods under simulated field conditions.

\section{Supplementary Information}

The online version contains supplementary material available at https://doi. org/10.1186/s13071-021-05055-z.

Additional file 1: Table S1. Percentage germination of Metarhizium anisopliae (ESALQ 818 and LEF 2000) blastospores when formulated with and without sunflower oil. Fig S1. Radial growth $(\mathrm{mm})$ of Metarhizium anisopliae (ESALQ 818 and LEF 2000) blastospores formulated with and without sunflower oil (20\%) over a 10 day period. Photograph of ovitrap used to collect Aedes aegypti eggs in the field.

\section{Acknowledgements}

We would like to acknowledge UENF for the post-doctoral grant awarded to LIS, CAPES for the post-doctoral grant awarded to ARP, and FAPERJ for the master's degree student grant awarded to AR. CPS and RIS are CNPq research fellows.

\section{Authors' contributions}

ARP and RIS: conceptualization; GAS, ARP and CPS: formal analysis; ARP, LIS and AP: investigation; GAS: data curation; RIS: funding acquisition; RIS: project administration; LIS and ARP: methodology; RIS and TMB: supervision; TMB: validation; RIS, TMB and ARP: writing —original draft; RIS and TMB: writing — review and editing. All authors read and approved the final manuscript.

\section{Funding}

This research was funded by FAPERJ: Fundação de Amparo à Pesquisa do Estado do Rio de Janeiro (E-26/201.336/2016; E26/202.923/2019) and CNPQ: Conselho Nacional de Desenvolvimento Científico e Tecnológico (440495/2016).

Availability of data and materials

All data is available from the corresponding author on request. 


\section{Declarations}

Ethics approval and consent to participate

This research did not include human subjects.

\section{Competing interests}

The authors declare that they have no competing interests.

\section{Author details}

${ }^{1}$ Laboratório de Entomologia e Fitopatologia, Universidade Estadual do Norte Fluminense Darcy Ribeiro, Campos dos Goytacazes, Rio de Janeiro 28013-602, Brazil. ${ }^{2}$ Departamento de Bioquímica, Universidade Federal de Santa Catarina, Florianópolis, Santa Catarina 88040-900, Brazil. ${ }^{3}$ Department of Biosciences, Swansea University, Wales SA2 8PP, UK.

Received: 21 July 2021 Accepted: 5 October 2021

Published online: 28 October 2021

\section{References}

1. Powell JR. Mosquito-borne human viral diseases: why Aedes aegypti? Am J Trop Med Hyg. 2018;98:1563-5.

2. Brady OJ, Gething PW, Bhatt S, Messina JP, Brownstein JS, et al. Refining the global spatial limits of dengue virus transmission by evidence-based consensus. PLoS NTD. 2012;6:e1760.

3. Jones R, Kulkarni MA, Davidson TMV, RADAM-LAC Research Team, Talbot B. Arbovirus vectors of epidemiological concern in the Americas: a scoping review of entomological studies on Zika, dengue and chikungunya virus vectors. PLoS ONE. 2020;15:e0220753.

4. Bhatt $S$, Gething P, Brady O, et al. The global distribution and burden of dengue. Nature. 2013;496:504-7.

5. Smith LB, Kasai S, Scott JG. Pyrethroid resistance in Aedes aegypti and Aedes albopictus: important mosquito vectors of human disease. Pest Biochem Physiol. 2016:133:1-12.

6. Benelli $\mathrm{G}$, Jeffries $\mathrm{CL}$, Walker T. Biological control of mosquito vectors: past, present, and future. Insects. 2016;7:52

7. Dahmana H, Mediannikov O. Mosquito-borne diseases emergence/ resurgence and how to effectively control it biologically. Pathogens. 2020;9:310

8. Samuels RI, Paula AR, Carolino AT, Gomes AS, Paula CO, Cypriano MBC Silva LEl, Ribeiro A, Santos JWAB, Silva CP. Entomopathogenic organisms: conceptual advances and real-world applications for mosquito biological control. Open Access Insect Physiol. 2016;6:25-31.

9. Thomas MB. Biological control of human disease vectors: a perspective on challenges and opportunities. Biocontrol. 2018:63:61-9.

10. Faria MR, Wraight SP. Mycoinsecticides and Mycoacaricides: a comprehensive list with worldwide coverage and international classification of formulation types. Biol Control. 2007;43:237-56.

11. Jaronski S, Mascarin GM. Mass production of fungal entomopathogens. In: Lacey LA, editor. Microbial control of insect and mite pests from theory to practice. Yakima: IP Consulting International; 2016. p. 141-55.

12. Lane BS, Trinci AP, Gillespie AT. Influence of cultural conditions on the virulence of conidia and blastospores of Beauveria bassiana to the green leafhopper, Nephotettix virescens. Mycol Res. 1991;95:829-33.

13. Hall RA. Pathogenicity of Verticillium lecanii conidia and blastospores against the aphid Macrosiphoniella sanborni. Entomophaga. 1979;12:191-8.

14. Vandenberg JD, Jackson MA, Lacey LA. Relative efficacy of blastospores and aerial conidia of Paecilomyces fumosoroseus against the Russian wheat aphid. J Invertebr Path. 1998:72:181-3.

15. Alkhaibari AM, Carolino AT, Bull JC, Samuels RI, Butt TM. Differential pathogenicity of Metarhizium blastospores and conidia against larvae of three mosquito species. J Med Entomol. 2017;54:696-704.

16. Morales-Reyes C, Mascarin GM, Jackson MA, Hall D, Sánchez-Peña SR, Arthurs SP. Comparison of aerial conidia and blastospores from two entomopathogenic fungi against Diaphorina citri (Hemiptera: Liviidae) under laboratory and greenhouse conditions. Biocontrol Sci Technol. 2018;28:737-49
17. Alkhaibari AM, Carolino AT, Yavasoglu SI, Maffeis T, Mattoso TC, Bull JC, Samuels RI, Butt TM. Metarhizium brunneum blastospore pathogenesis in Aedes aegypti larvae: attack on several fronts accelerates mortality. PLoS Pathog. 2016;12:e1005715.

18. Carolino AT, Gomes SA, Teodoro TBP, Mattoso TC, Samuels RI. Aedes aegypti pupae are highly susceptible to infection by Metarhizium anisopliae blastospores. J Pure Appl Microbiol. 2019;13:1629-34.

19. Paula AR, Brito ES, Pereira CR, Carrera MP, Samuels RI. Susceptibility of adult Aedes aegypti (Diptera: Culicidae) to infection by Metarhizium anisopliae and Beauveria bassiana: prospects for Dengue vector control. Biocontrol Sci Technol. 2008;18:1017-25.

20. Lee JY, Woo RM, Choi CJ, Shin TY, Gwak WS, Woo SD. Beauveria bassiana for the simultaneous control of Aedes albopictus and Culexpipiens mosquito adults shows high conidia persistence and productivity. AMB Express. 2019;9:206

21. Mnyone LL, Koenraadt CJ, Lyimo IN, Mpingwa MW, Takken W, Russell TL. Anopheline and culicine mosquitoes are not repelled by surfaces treated with the entomopathogenic fungi Metarhizium anisopliae and Beauveria bassiana. Parasites Vectors. 2010;3:1-6.

22. Silva LEI, Paula AR, Ribeiro A, Butt TM, Silva CP, Samuels RI. A new method of deploying entomopathogenic fungi to control adult Aedes aegypti mosquitoes. J Appl Entomol. 2018;142:59-66.

23. Paula AR, Ribeiro A, Silva CP, Silva LEI, Butt TM, Samuels RI. Improving the delivery and efficiency of fungus-impregnated cloths for control of adult Aedes aegypti using a synthetic attractive lure. Parasites Vectors. 2018;11:285-91.

24. Carolino AT, Paula AR, Silva CP, Butt TM, Samuels RI. Monitoring persistence of the entomopathogenic fungus Metarhizium anisopliae under simulated field conditions with the aim of controlling adult Aedes aegypti (Diptera: Culicidae). Parasites Vectors. 2014;7:198.

25. Paula AR, Carolino AT, Silva CP, Pereira CR, Samuels RI. Testing fungus impregnated cloths for the control of adult Aedes aegypti under natural conditions. Parasites Vectors. 2013:6:256.

26. Tjaden NB, Thomas SM, Fischer D, Beierkuhnlein C. Extrinsic incubation period of dengue: knowledge, backlog, and applications of temperature dependence. PLoS NTD. 2013;7(6):5.

27. Scholte E-J, Knols BGJ, Takken W. Infection of the malaria mosquito Anopheles gambiae with the entomopathogenic fungus Metarhizium anisopliae reduces blood feeding and fecundity. J Invertebr Pathol. 2006;91:43-9.

28. Vega FE, Jackson MA, McGuire MR. Germination of conidia and blastospores of Paecilomyces fumosoroseus on the cuticle of the silverleaf whitefly, Bemisia argentifolii. Mycopathologia. 1999;147:33-5.

29. Kryukov VY, Yaroslavtseva ON, Whitten MM, Tyurin MV, Ficken KJ, Greig C, Melo NR, Glupov W, Dubovskiy IM, Butt TM. Fungal infection dynamics in response to temperature in the lepidopteran insect Galleria mellonella. Insect Sci. 2018:25:454-66.

30. Grizanova EV, Coates CJ, Dubovskiy IM, Butt TM. Metarhizium brunneum infection dynamics differ at the cuticle interface of susceptible and tolerant morphs of Galleria mellonella. Virulence. 2019;10:999-1012.

31. Alves RT, Bateman RP, Gunn J, Prior C, Leather SR. Effects of different formulations on viability and medium-term storage of Metarhizium anisopliae conidia. Neotrop Entomol. 2002;31:91-9.

32. Skinner M, Parker BL, Kim JS. Role of entomopathogenic fungi in integrated pest management. In: Abrol DP, editor. Integrated pest management. New York: Academic Press; 2014. p. 169-91.

33. Lomer CJ, Bateman RP, Johnson DL, Langewald J, Thomas M. Biological control of locusts and grasshoppers. Ann Rev Entomol. 2001;46:667-702.

34. Blanford S, Chan BHK, Jenkins N, Sim D, Turner RJ, Read AF, Thomas MB. Fungal pathogen reduces potential for malaria transmission. Science. 2005;308:1638-41.

35. Kleespies RG, Zimmermann G. Viability and virulence of blastospores of Metarhizium anisopliae (Metch.) Sorokin after storage in various liquids at different temperatures. Biocontrol Sci Technol. 1994:4:309-19.

36. Leemon DM, Jonsson NN. Laboratory studies on Australian isolates of Metarhizium anisopliae as a biopesticide for the cattle tick Boophilus microplus. J Invertebr Pathol. 2008;97:40-9.

37. Ibrahim L, Butt TM, Beckett A, Clark SJ. The germination of oil-formulated conidia of the insect pathogen, Metarhizium anisopliae. Mycol Res. 1999;103:901-7. 
38. Prior C, Jollands P, Le Patourel G. Infectivity of oil and water formulations of Beauveria bassiana (Deutromycotina: Hyphomycetes) to the cocoa weevil pest Pantorhytes plutus Coleoptera: Curculionidae). J Invertebr Pathol. 1988;52:66-72.

39. Magan N. Physiological approaches to improving the ecological fitness of fungal biocontrol agents. In: Butt TM, Jackson CW, Magan N, editors. Fungi as biocontrol agents. Oxon: CAB Publishing; 2001. p. 239-325.

40. Maldonado-Blanco MG, Gallegos-Sandoval JL, Fernández-Peña G, Sandoval-Coronado CF, Elías-Santos M. Effect of culture medium on the production and virulence of submerged spores of Metarhizium anisopliae and Beauveria bassiana against larvae and adults of Aedes aegypti (Diptera: Culicidae). Biocontrol Sci Technol. 2014;24:180-9.

41. Carolino AT, Teodoro TBP, Gomes SA, Silva CP, Samuels RI. Production of conidia using different culture media modifies the virulence of the entomopathogenic fungus Metarhizium against Aedes aegypti larvae. J Vector Borne Dis. 2021. https://doi.org/10.4103/0972-9062.318315.

42. Mascarin GM, Jackson MA, Behle RW, Kobori NN, Delalibera JI. Improved shelf life of dried Beauveria bassiana blastospores using convective drying and active packaging processes. Appl Microbiol Biotechnol. 2016;100:8359-70.

\section{Publisher's Note}

Springer Nature remains neutral with regard to jurisdictional claims in published maps and institutional affiliations.
Ready to submit your research? Choose BMC and benefit from:

- fast, convenient online submission

- thorough peer review by experienced researchers in your field

- rapid publication on acceptance

- support for research data, including large and complex data types

- gold Open Access which fosters wider collaboration and increased citations

- maximum visibility for your research: over $100 \mathrm{M}$ website views per year

At BMC, research is always in progress.

Learn more biomedcentral.com/submissions 